\title{
LA INTEGRIDAD
}

EN LA DOCENCIA:

DIÁLOGO CON

CARLOS DE LA ISLA

José Rafael González Díaz*

"Llamamos liberales los estudios que son dignos de un hombre libre, aquellos por los que se busca y ejercita la sabiduría y no el lucro y el placer que

son los estímulos de la acción de los caracteres vulgares. La educación es liberal porque libera de la esclavitud de los exclusivos intereses utilitarios

y es humanista en cuanto forma la humanitas. "'

\section{En camino a la entrevista}

$$
\text { La ciudad es el espacio privilegiado }
$$

en el que sea amalgaman los valores y la historia de una comunidad. Los hombres y las mujeres construyen juntos de modo peculiar ese espacio en el que se desarrollan y enriquecen su personalidad.

Las calles, los jardines y las plazas son un testimonio del modo en el que las personas se relacionan. Los barrios como agrupaciones sociales espontáneas tienen un carácter peculiar que los distingue de otros; puede tratarse de su distribución y geografía, su composición socioeconómica o la cultura que los identifica. Algunos barrios o pueblos destacan por la belleza de sus edificios; otros, por los acontecimientos históricos de los que fueron testigos o por la cultura viva que los

* Departamento Académico de Estudios Generales, ITAM.

${ }^{1}$ Pier Paolo Vergerio, "De ingenuis moribus et liberalibus adulescentiae studiis" (De las buenas costumbres y los estudios liberales), en Humanist Educational Treatises, 2002, Cambridge, Harvard University Press, editor y traductor Craig Kallendorf, p. 29. 
caracteriza. El barrio de San Ángel y el conjunto urbano arquitectónico de Tizapán, Altavista y Chimalistac, son lugares que parecen resistir el paso del tiempo y tienen una atmósfera en la que se conserva el eco de otras épocas. El pasado indígena, el proyecto novohispano, el México del siglo XX en la forma de una cultura que sigue viva en sus plazas, museos y mercados.

Cuando le solicité una entrevista a Carlos de la Isla no me imaginé que se realizaría en su casa ni que para llegar desde el ITAM no tenía sino que caminar unos minutos. Como si la vida del ITAM y del doctor De la Isla estuvieran ligadas espacialmente: el profesor viviendo en la universidad y la universidad extendiéndose por las calles que le circundan. Caminé por el empedrado rodeado de esas casonas coloniales que fusionan los estilos españoles con las técnicas y materiales de los indígenas hasta lograr la síntesis de una identidad propia.

Disfruté de sus callejuelas y de las bugambilias intensamente coloreadas de blanco, magenta y púrpura. La entrevista quedó fijada para el 2 de mayo de 2017 a las 11:00 de la mañana. Llegué minutos antes y un vecino me facilitó el acceso al conjunto habitacional. Las $10 \mathrm{o}$ 15 casas tienen una construcción uniforme de ladrillo crudo que ofrece al 130 visitante un sentido de orden, sobriedad y belleza. La palabra integridad, que proviene del latín integritas, integritatis, y que se traduce como totalidad, robustez, buen estado físico, honestidad y rectitud, es la más apropiada para describir el espacio en el que están tanto el doctor De la Isla como el ITAM y en el que se desarrolló la entrevista.

El doctor Carlos de la Isla me recibió amablemente, y por contratiempos con la llave, tuve la fortuna de conocer a su esposa, que gentilmente nos ayudó. Lo noté fuerte, sereno y lleno de energía. Empezamos a conversar, le dije que me interesaba hablar sobre su aportación en el ITAM, de manera especial en la configuración y consolidación del Departamento de Estudios Generales. 


\section{Los inicios en el ITAM}

José Rafael González — Profesor, ¿me podría platicar un poco de su llegada al ITAM y de su aportación en la configuración y consolidación del Departamento de Estudios Generales y de los cursos que imparte? Carlos de la Isla - Cuando regresé de Europa (estuve en Europa 12 años) me casé. Vivimos un tiempo en Los Ángeles y al llegar a México comencé a dar clases en la Universidad Iberoamericana. Ahí conocí al profesor José Ramón Benito, que fue mi alumno, y a Jaime Ruiz de Santiago, que no fue mi alumno. También, casi de inmediato, empecé a colaborar con el Instituto Politécnico Nacional y la UNAM. La situación del país era difícil. Se percibía la necesidad de un cambio y los estudiantes comenzaban a cuestionar ese orden injusto. El profesor José Ramón Benito me invitó a venir al ITAM. Llegué cuando se estaban modificando los cursos de Estudios Generales.

¿Qué significa ser un maestro? ¿Qué se quiere expresar cuando se dice que no se puede ser un docente si no se tiene vocación? A la docencia se le atribuye la más alta dignidad y se la separa del resto de las profesiones. Algunos hablan de "vocación" como del signo de identidad más definitorio del quehacer de los profesores. La palabra "vocación" proviene del verbo latino vocare y significa "llamar". Algo o alguien mueve la voluntad de una persona para realizar una misión. De hecho, el verbo castellano "llamar" viene también del latín clamare y literalmente significa "gritar". Por eso, más allá de las connotaciones que la palabra "vocación" puede tener en algunos contextos religiosos, el término se conserva en la esfera secular para hacer referencia a la misión o llamado que recibe un sujeto (o inclusive una institución) para ser de determinada manera y luego actuar conforme a esa identidad. La Real Academia de la Lengua Española define la palabra "vocación" como la “inspiración con que Dios llama a algún estado" o como la "inclinación a un estado, una profesión o una carrera". ${ }^{2}$

${ }^{2}$ Diccionario de la Real Academia de la Lengua Española, en $<$ http://dle.rae.es/srv/ search?m=30\&w=vocaci $\%$ C3\%B3n>. Consultado el 13 de junio de 2017 . 
La vocación se descubre y se cultiva conforme la persona despliega su identidad. Se va fraguando a medida que descubrimos nuestro propio ser. No es un puro quehacer sin alma, sino el ser que se exterioriza en nuestras obras. De lo que somos se sigue lo que hacemos y lo que hacemos nos va conformando cada día más. Tal como lo expresa Aristóteles cuando habla de la virtud: "Las virtudes, por tanto, no nacen en nosotros ni por naturaleza ni contrariamente a la naturaleza, sino que siendo nosotros naturalmente capaces de recibirlas, las perfeccionamos en nosotros por costumbre". ${ }^{3}$ La sustancia de la vocación docente abarca todas las dimensiones de la persona y no puede reducirse al mero empleo que obtiene un profesionista para garantizar el sustento ni al puro despliegue de la inteligencia. El docente vive de tal manera que su ser y su obrar coinciden. Se hace docente al mismo tiempo que actúa y vive como docente. Dice Aristóteles:

Las virtudes, en cambio, las adquirimos ejercitándonos primero en ellas, como pasa también en las artes y oficios. Todo lo que hemos de hacer después de haber aprendido, lo aprendemos haciéndolo, como por ejemplo, llegamos a ser arquitectos construyendo y citaristas tañendo cítara. Y de igual manera nos hacemos justos practicando actos de justicia y temperantes haciendo actos de templanza y valientes haciendo actos de valentía. ${ }^{4}$

Cuando el doctor De la Isla llegó a México, estaba clara su vocación por la docencia. Solo faltaba encontrar el lugar idóneo para ejercerla. En ese momento tuvo la oportunidad de enriquecerse como docente impartiendo cátedra en otras universidades de México. Al final, el ITAM y el doctor Carlos de la Isla convergieron en el humanismo que sustenta los objetivos y la filosofía educativa del ITAM. Así lo expresó el 23 de febrero de 2006, en una conferencia titulada Estudios Generales: Universidad dentro del tecnológico, con motivo de las celebraciones por los 60 años de vida académica del ITAM:

Hace casi 34 años fui invitado por el profesor José Ramón Benito a participar en la labor educativa del ITAM. Él coordinaba entonces, creo que con calidad y lucidez, lo que podría llamarse un renacimiento del

${ }^{3}$ Aristóteles, Ética Nicomaquea, Libro II, 1.

${ }^{4}$ Loc. cit. 
Departamento de Estudios Generales. Mi primer impulso fue de resistencia, porque ya tenía una fuerte carga académica en la UNAM y en el IPN. El profesor Benito amablemente insistió. Recuerdo entonces que pregunté sobre la real, auténtica y razonable libertad de cátedra y por los objetivos y filosofía educativa del ITAM. El profesor Benito pronto me aseguró una entera libertad de cátedra y poco después me proporcionó los documentos. $^{5}$

La primera reflexión del doctor De la Isla que se publicó en el ITAM fue una profunda especulación sobre los vínculos inseparables entre la formación integral y la educación superior. El artículo lleva por título "Reflexiones en plural sobre un camino hacia lo humano en la educación superior" $\mathrm{y}$ fue publicado un año después de su llegada al ITAM. El texto se ancla en las experiencias que él mismo había acumulado en esos años de ebullición universitaria en México y en el mundo. Él mismo acompañó a sus estudiantes en las protestas de 1968. El esfuerzo de pensar a la universidad como conciencia crítica de la sociedad nacía de sus necesidades vitales y no de un capricho intelectual. De acuerdo con una de las consignas enarboladas durante el convulso mayo parisino, los jóvenes decían: "Seamos realistas, pidamos lo imposible". Riguroso en el planteamiento de la problemática y haciendo una cuidadosa revisión histórica, el artículo ofrece una respuesta al problema de la universidad con frescura y sin caer en academicismos.

La pregunta de su primer artículo en el ITAM tiene como núcleo un tema fundamental que sigue vigente en la filosofía de la educación y en los debates en torno a la naturaleza de la educación universitaria. ¿La universidad debe tener como objetivo la formación de la persona para una vida libre y responsable en todas sus dimensiones - intelectual, moral, estética e incluso espiritual — o debe concentrar sus energías en la preparación técnica profesional de los individuos que reclama el mercado como instrumento para el desarrollo económico?

Carlos de la Isla responde con la afirmación de que la dignidad humana debe primar sobre cualquier sistema económico, social o político, y

${ }^{5}$ Carlos de la Isla, "Estudios Generales: Universidad dentro del tecnológico", Estudios 78 (2006), p. 102.

${ }^{6}$ Carlos de la Isla, "Reflexiones en plural sobre un camino hacia lo humano en la educación superior”, Revista del Instituto Tecnológico Autónomo de México 1 (1973), pp. 4-13. 
que tratar a las personas como mercancías siempre será una injusticia que debemos abolir. En la Fundamentación de la metafisica de las costumbres, Kant señala que las cosas pueden tener precio o dignidad. Aquello que tiene precio es intercambiable, perfectamente sustituible. Lo que se halla por encima de todo precio y no tiene equivalencia es lo que posee dignidad. $^{7}$

Sin embargo, no debe entenderse la dignidad como una palabra hueca, sino como un criterio que debe regir la vida práctica. Su fundamento está en que la naturaleza racional existe como fin en sí mismo. Así, la vida practica debe tener como imperativo: "obra de tal modo que uses a la humanidad, tanto en tu persona como en la persona de cualquier otro, siempre al mismo tiempo como fin y nunca simplemente como medio". 8

El concepto de "dignidad humana" tiene una larga historia, no exenta de polémicas, y su significado va más allá del uso técnico que puedan darle algunos filósofos. Por ejemplo, Jürgen Habermas sostiene que si bien el concepto aparece más tarde que el de derechos humanos como componente jurídico, existe desde el principio una estrecha relación conceptual, y la dignidad humana constituye la fuente moral de la que se nutre el contenido de todos los derechos fundamentales. ${ }^{9}$

Parce que algunas de las metáforas y reflexiones que encontramos en el discurso de Carlos de la Isla son la manera en que un gran humanista nos invita a distinguir entre el ser y el tener, entre el valor de las personas y las cosas y en la correcta relación de la calidad frente a la cantidad. Se trata de una invitación a ordenar la vida personal y social colocando cada cosa según sus fines. El objetivo es que el hombre y la ciudad vivan en la justicia y alcancen la felicidad. De ese modo lo expresa Platón en la República:

Respecto a su acción interna; es ella [la justicia] la que no permite que ninguna de las partes del alma haga lo que no le compete ni que se

${ }^{7}$ Immanuel Kant, Fundamento para una metafísica de las costumbres, 2012, Madrid, Alianza Editorial, trad. y estudio preliminar de Roberto R. Aramayo, p.148.

${ }^{8}$ Ibid., p. 139.

${ }^{9} \mathrm{Cfr}$. Jürgen Habermas, "La idea de dignidad humana y la utopía realista de los derechos humanos”, Anales de la Cátedra Francisco Suárez 44 (2010), pp. 105-121. 
entremeta en cosas propias de otro linajes, sino que, ordenando debidamente lo que corresponde, se rige a sí misma y se hace su mejor amiga al establecer el acuerdo entre los tres elementos [prudencia, valor, templanza] como si fuesen los términos de una armonía, el de la cuerda grave, el de la alta y el de la media, y todos los demás tonos intermedios, si es que existen. ${ }^{10}$

En las Leyes, Platón describe ese orden armonioso que debe orientar las preocupaciones de todo hombre:

Por esta razón, más de una vez hemos dicho que la preocupación de las riquezas debe ser estimada tan solo en último lugar, pues, sobre tres cosas que acaparan todas las preocupaciones de los hombres, la del dinero no es más que la tercera y última, y eso suponiendo que se trata de una solicitud lícita; es el cuidado del cuerpo el que ocupa el lugar intermedio, mientras que al alma le corresponde la primera de estas preocupaciones. ${ }^{11}$

Este orden y equilibrio entre las partes de un conjunto es lo que llamamos “armonía”. En la música, la armonía es el modo en el que se articulan las notas, los acordes, etc. Ese equilibrio y perfección es lo que admiramos en la obra de compositores como Mozart. ${ }^{12}$ Del mismo modo, la universidad y la educación permiten la excelencia del hombre que alcanza la unidad del ser, del bien y que se traduce en la belleza moral. Es la universidad el espacio privilegiado para descubrir la propia armonía y la belleza que emana del orden justo.

JRG - ¿Cómo describiría este proceso de revisión y transformación de los cursos que se impartían en el departamento de Estudios Generales?

CI - Pienso que en este proceso se trató de conservar el espíritu de los cursos [que se impartían en la Universidad de Nuevo León]. Al

${ }^{10}$ Platón, La República, Libro V, XVI.

${ }^{11}$ Platón, La República, Libro V.

${ }^{12}$ Algunos críticos de música coinciden en que la obra Mozart es un momento culminante en el que luz, oscuridad y pasión se funden de manera excelente y elegante. Cfr. Nikolaus Harnoncourt, El diálogo musical. Reflexiones sobre Monteverdi, Bach y Mozart, 2003, Barcelona, Paidós; Diálogos sobre Mozart. Reflexiones sobre la actualidad de la música, 2016, Barcelona, Acantilado. 
principio, las antologías se conservaron casi de forma íntegra. Fue ahí, en la reestructuración, cuando se formó un equipo de trabajo en el que participaban el profesor Ramón Zorrilla (1925-1989), el profesor José Ramón Benito y su servidor. Después se incorporaron Franz Oberarzbacher Niederwolfsgruber y Luis Astey (1921-1997). Yo participé cuando me incorporé al ITAM como profesor de tiempo completo en 1972. Al principio me resistía, porque tenía muchas clases, pero al final terminé por unirme como profesor de tiempo completo. Recuerdo que solo había dos grupos de nuevo ingreso, así que de manera simultánea dábamos las clases y preparábamos los cursos.

Las antologías a las que se refiere el doctor Carlos de la Isla fueron los materiales de apoyo que se utilizaron para impartir el curso de Evolución de la Civilización Contemporánea en la facultad de economía de la Universidad de Nuevo León. La incorporación en México de los cursos de Estudios Generales fue promovida y apoyada por la primera generación de economistas, para resolver las dificultades y los yerros de la enseñanza económica en el país. ${ }^{13}$

La idea de adaptar estos cursos en la formación de los economistas fue de Daniel Cosío Villegas (1898-1976). La gestión del primer proyecto fue de Consuelo Meyer L'Eppé (1918-2010) y el esfuerzo inicial de adaptación quedó a cargo de un grupo de jóvenes humanistas de la Universidad de Nuevo León. ${ }^{14}$ El punto de partida de esta historia es el año 1958, cuando en la Facultad de Economía de la Universidad de Nuevo León se decidió impartir el curso Evolución de la Civilización Contemporánea. Se trataba de la adaptación del curso Civilización Occidental Contemporánea que se ofrecía en el Columbia College. Dice Consuelo Meyer: "Yo pensé que ese curso tenía un gran porvenir. Lo mandé a diversas universidades de América Latina con el fin de que si se interesaban, lo adoptaran y aprovecharan. Puse especial hincapié en matemáticas y estadística, y en este curso que era hijo de mi alma

${ }^{13}$ Cfr. José Rafael González Díaz, "El nacimiento de los estudios generales en México: la Universidad de Nuevo León", texto sometido a dictamen en Estudios.

${ }^{14}$ Cfr. Rodolfo Vázquez, "Un enfoque liberal de la educación”, Estudios 30 (1992), pp. 81-92. 
de Civilización Contemporánea" ${ }^{15}$ Como señala Meyer, "esta facultad [Economía de Nuevo León] tiene una deuda de gratitud con Daniel Cosío Villegas, inspirador de la idea de realizar esta obra y colaborador de la misma en muy variadas formas". ${ }^{16}$

Este curso Evolución de la Civilización Contemporánea fue una de las novedades en la reforma del plan de estudios de la Facultad de Economía de Nuevo León, que seguía de cerca las reflexiones de Daniel Cosío Villegas en "Errores y soluciones en la enseñanza económica" ${ }^{17}$

En una de las últimas entrevistas que ofreció la maestra Consuelo Meyer, retoma la misma idea: "Se introdujo por sugestión de don Daniel Cosío Villegas un curso de civilización contemporánea que se daba en la Universidad de Columbia de Estados Unidos". ${ }^{18}$ Este curso tenía dos pilares: el método dialógico y las antologías. Su implantación en la Universidad de Nuevo León comenzó con un intenso esfuerzo de selección, traducción y preparación de las antologías para el curso. Los materiales del curso se distribuían en 26 volúmenes cuya extensión promedio era de unas 150 páginas. El día de hoy estas antologías son casi imposibles de conseguir. Las lecturas estaban estructuradas temática e históricamente. Cada volumen tenía dos partes: un estudio de carácter expositivo o de interpretación de uno de los temas del curso que llevaba el nombre de ensayo, y una selección de textos originales que ilustraba el tema y que era conocida como lecturas. Es otro de los atributos que hay que destacar, que no se trataba de colocar lecturas de segunda mano, sino textos originales.

Cuando el doctor De la Isla se incorporó al ITAM, esos materiales se encontraban en revisión y transformación. Los cursos que se habían impartido en la Universidad de Nuevo León tenían como objetivo principal el desenvolvimiento intelectual del estudiante para que emitiera juicios independientes y con sentido de responsabilidad. Se quería que

${ }^{15}$ Consuelo Meyer, "Plática con la Srita. Consuelo Meyer", Contrapunto 2, 2007, pp. 23-24.

${ }^{16}$ Consuelo Meyer, "Prólogo", en Evolución de la Civilización Contemporánea, capítulo I, 1963, México, Comité Editorial del Curso de Civilización Contemporánea, Facultad de Economía, Universidad de Nuevo León, p. XXVIII.

${ }^{17}$ Cfr. Daniel Cosío Villegas, "Errores y soluciones en la enseñanza económica”, Boletín del Banco de Venezuela 35-36 (enero-febrero de 1948), pp. 10-14.

${ }^{18}$ Meyer, "Plática con la Srita. Consuelo Meyer", pp. 23-24. 
el alumno fortaleciera su capacidad de análisis, síntesis y expresión crítica. Por eso, el objetivo estaba íntimamente vinculado a un "método" que favorecía el estudio independiente de los alumnos y su participación activa. ¿Qué quiere decir "desenvolvimiento intelectual”? No se quería que el estudiante se pusiera en condiciones de repetir una lección o un contenido ni que fuera dócil a las conclusiones defendidas por el profesor, sino que se buscaba la reducción gradual de la dirección del profesor hasta casi desaparecer y que el "estudiante alcanzara la plenitud de su capacidad para pensar por sí mismo y [pudiera] enfrentarse a los problemas intelectuales de forma independiente, con lo que quedaría resuelto uno de los grandes problemas de su educación". ${ }^{19}$

Este desenvolvimiento intelectual tenía que darle prioridad al pensamiento crítico y no a los procesos memorísticos. Así lo describe el doctor De la Isla:

Cuando por el contrario, lo que se pretende es el cambio, cuando se quiere favorecer el desarrollo de personas que piensan, que cuestionan, que proponen alternativas; cuando lo que se busca es la lucidez del pensamiento crítico, de la imaginación creadora, de la invención sin límites [...] el método, el camino es radicalmente diferente. No es la memoria la facultad privilegiada y consentida sino el quehacer de la inteligencia, el ejercicio predilecto y estimulado de la invención. La relación maestro-alumno no es vertical, profética y reverente, sino entre personas de igual dignidad humana que en el diálogo dan testimonio de humanidad. En este método la sustancia educativa es el testimonio de vida, la verdad de la vida, la exigencia de la vida. Es diálogo existencial, porque no está hecho meramente de palabras, sino de existencia y convicciones. ${ }^{20}$

El comité académico al que se integró el doctor De la Isla tomó como punto de partida la experiencia de la Universidad Nuevo León para hacer algo original. Efectivamente, los materiales de Nuevo León eran muy semejantes a los del curso de Civilización Occidental Contem-

${ }^{19}$ Meyer, "Prólogo", p. XIV.

${ }^{20}$ Carlos de la Isla, "Nota sobre los estudios generales", en De esclavitudes y libertades. Ensayos de ética, educación y politica, 2006, México, ITAM/Porrúa, p. 117. 
poránea que ofrecía el Columbia College, ${ }^{21}$ no obstante, en los casos de Nuevo León y del ITAM la adaptación fue una creación propia: "solo en raras ocasiones se decidió conservar los ensayos del curso de Columbia College". ${ }^{22}$ Esto quiere decir que el establecimiento de los Estudios Generales en México no fue una traducción literal, sino una verdadera creación en la que cada institución puso algo original en el marco de un mismo espíritu.

\section{Sin esta pasión, la educación no vale la pena de ser vivida, no vale la pena ni de ser pensada}

JRG — ¿Cuál piensa que fue su aportación al Departamento de Estudios Generales y al ITAM?

CI - Impartiendo clase, acompañando las inquietudes de mis alumnos. Me siento honrado de haber recibido el nombramiento de Profesor Emérito y ahora, todavía más, por haber dado mí nombre a un aula del ITAM. Yo lo agradezco porque es un homenaje al humanismo, a la dignidad humana y a la libertad. Mi trabajo fue el testimonio de la crítica, como le decía, y de la revisión de los cursos de ideas y posteriormente de problemas.

La distinción de emérito que otorga el ITAM está destinada a los miembros del personal académico que han realizado una labor eminente en las actividades académicas del Instituto y reconoce la calidad humana del galardonado y su espíritu de servicio. Los eméritos son un modelo para los demás miembros del claustro académico y para el resto de la comunidad. El doctor De la Isla recibió esta alta distinción en 1998. En la ceremonia de nombramiento fue reconocido por el humanismo vibrante que acompaña su docencia y por la razón impregnada de sentimiento que caracteriza su rigor académico. El rector Arturo Fernández dijo:

Finalmente, comprendí que el doctor Carlos de la Isla, como todos aquellos hombres con una formación clásica en las humanidades que asumen

${ }^{21}$ Este curso se ofrecía desde 1920. Para conocer su historia, es inestimable el texto de Justus Buchler, "Reconstruction in the liberal arts".

${ }^{22}$ Meyer, "Prólogo", p. XIV. 
una responsabilidad y compromiso con la humanidad en cuanto al destino de la civilización, son, en realidad, hombres de todos los tiempos [...] Su pasión por el destino de la civilización, por la justicia y la libertad es manifiesta y contundente en cada sesión de clase. Su vehemencia en contra de la deshumanización de la civilización moderna y sus consecuencias es memorable. ${ }^{23}$

Los cursos de Ideas e Instituciones Políticas y Sociales y de Problemas de la Civilización Contemporánea le parecen de una importancia primordial para la formación que se proponen las universidades. Los estudiantes deben conocer sus problemas y comprometerse en la construcción de un mundo mejor.

Estos cursos son apasionantes para todos los hombres que aman al mundo y a todos los hombres del mundo; para los que aman la vida, los encantos de la vida; para todos los que aman la justicia, la paz, la libertad y que por eso odian la guerra, la violencia, la adoración al dinero hasta el desprecio de las personas. ${ }^{24}$

Sin embargo, para Carlos de la Isla estos cursos no se resuelven en un círculo interminable de tragedias, sino que conocidos los conflictos en toda su realidad, maestros y alumnos deben realizar un análisis crítico y juzgar sobre la su naturaleza, causas y complejidad:

Y después, la tarea más importante: descubrir, construir, imaginar, inventar soluciones; crear utopías de los dos estilos: utopías que denuncian y anuncian (Freire), pero también las otras de los ideales tan altos que, aunque inalcanzables, ayudan a caminar hacia lo alto [Kant]. ${ }^{25}$

Efectivamente, Paulo Freire dedicó su último libro al tema de la indignación, ${ }^{26}$ que no se refiere a la rabia que se agota dentro de sí ni

${ }^{23}$ Arturo Fernández, "Discurso en la ceremonia de nombramiento de profesor emérito al doctor Carlos de la Isla Veraza", Estudios 122 (2017), pp. 44-45.

${ }^{24}$ Carlos de la Isla, "Educación, universidad y los problemas de la civilización contemporánea".

${ }^{25}$ Loc. cit.

${ }^{26}$ Pablo Freire, Pedagogía de la indignación, 2001, Madrid, Morata. 
a la violencia, sino al $\theta v \mu o ́ s$, la ira de la que hablaba Aristóteles para señalar esa fuerza o coraje que se despierta frente a la injusticia. ${ }^{27} \mathrm{En}$ la cosmovisión griega se distinguían dos entidades anímicas. Por un lado,

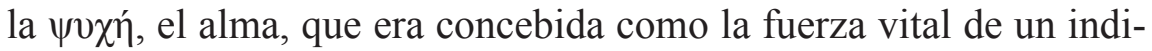
viduo, y por el otro, el $\theta v \mu o ́ s$, la parte del alma en la que residen las

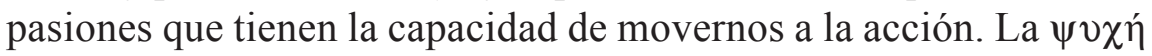
estaba asociada con la percepción personal y subjetiva de una realidad profunda, impersonal e incluso fría. En contraste, el $\theta v \mu o ́ \varsigma$ se relacionaba con las emociones y la calidez, y tenía un carácter claramente social, porque esa radicalidad y pasión se muestra y se valida ante la comunidad. ${ }^{28}$

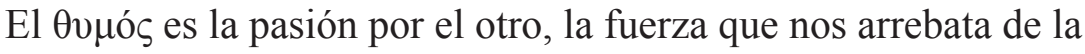
comodidad y nos lleva a constituir la comunidad, el verdadero motor para luchar por la justicia con esperanza. ${ }^{29}$ La pedagogía de la indignación es una reflexión sobre el coraje frente a la injusticia que nos invita a transformar la realidad a partir de la solidaridad y la esperanza. Por eso, para Freire la educación debe articular la denuncia y el anuncio, la utopía y el sueño. Si se renuncia al sueño y la utopía, lo único que queda es la reducción de la educación al entrenamiento técnico. ${ }^{30} \mathrm{El}$

${ }^{27}$ De manera análoga se expresa Luis Villoro: "Partamos por lo pronto de una realidad: la vivencia del sufrimiento causado por la injusticia. El dolor físico o anímico es una realidad de nuestra experiencia cotidiana. Pero hay una experiencia vivida particular: la de un dolor causado por el otro. Solo cuando tenemos la vivencia de que el daño sufrido en nuestra relación con los otros no tiene justificación, tenemos una percepción clara de la injusticia. La experiencia de la injusticia expresa una vivencia originaria: la vivencia de un mal injustificado, gratuito". "Una vía negativa hacia la justicia", en Los retos de la sociedad por venir. Ensayos sobre justicia, democracia y multiculturalismo, 2007, México, FCE, p. 16.

${ }^{28}$ Cfr. Jan Bremmer, El concepto del alma en la antigua Grecia, 2002, Madrid, Siruela, trad. de Menchu Gutiérrez, p. 49.

${ }^{29} \mathrm{Al}$ respecto, el afamado filósofo coreano Byung-Chul Han reflexiona sobre las relaciones entre eros, thymós y política, y advierte que la mediocridad en la política se debe a la agonía del eros y la primacía del deseo como epithymia sobre el resto de las entidades anímicas. "El Eros, que, según Platón, dirige el alma, tiene poder sobre todas sus partes: deseo (epithymia), valentía (thymós) y razón (logos). Cada parte del alma tiene su propia experiencia del placer e interpreta lo bello de forma propia en cada caso. Hoy parece que es sobre todo el deseo (epithymia) el que domina la experiencia del placer del alma. Por eso las acciones pocas veces están impulsadas por el valor (thymós). Es timótica, por ejemplo, la ira, que rompe radicalmente con lo establecido y hace comenzar un nuevo estado." Agonía del Eros, 2012, Barcelona, Herder, p. 66.

${ }^{30} \mathrm{Cfr}$. Freire, "Denuncia, anuncio, profecía, utopía y sueño", en Pedagogía de la indignación, pp. 129-146. 
$\theta v \mu$ ós es el único que posibilita "una sociedad menos fea y menos agresiva, en la cual podamos ser más nosotros mismos, tiene una práctica de real importancia en la formación democrática". ${ }^{31}$ Sobre esto mismo ha reflexionado el filósofo alemán Peter Sloterdijk en Ira y tiempo, donde dice:

En concordancia con los impulsos platónicos, también Aristóteles habla de la cólera como de algo beneficioso. A este afecto le extiende un certificado sorprendentemente favorable siempre y cuando esté aliada con el coraje y se mueva hacia una defensa razonable frente a las injusticias. En parte, la ira legítima conserva todavía un "oído de la razón", aun cuando a menudo eche a correr como un criado precipitado que no escucha del todo su encargo. Solo se convertiría en problemática si está acompañada de la incontinencia y se desborda en el exceso. "La ira es necesaria, de nada se triunfa sin ella, si no llena al alma, si no calienta el corazón; debe, pues, servirnos, no como jefe, sino como soldado". 32

Por eso no resulta extraño que el doctor Carlos de la Isla haya propuesto la frase de Hegel: "Nada grande se ha hecho en el mundo sin pasión", ${ }^{33}$ para roturar las paredes del ITAM. Algunas de esas frases provocativas que encontramos a lo largo del campus del ITAM, en los muros de la librería y la cafetería, fueron una sugerencia suya y quieren convocar a la inteligencia y a la voluntad del estudiante y de toda la comunidad del ITAM a perseguir los elevados ideales de ser cada día un mejor ser humano.

Se necesita la pasión que se propone lo que para el mundo parece imposible con la energía que desborda las medidas del mundo de medidas. Pasión por ideales aun inalcanzables; pasión por la verdad que desprecia

${ }^{31}$ Paulo Freire, Pedagogía de la autonomía. Saberes necesarios para la práctica educativa, 1966, México, Siglo XXI, p. 43.

${ }^{32}$ Séneca, Sobre la ira, libro I, capítulo IX, trad. de Francisco Navarro Calvo, Biblioteca Virtual Miguel de Cervantes, en $<$ http://www.cervantesvirtual.com/obra-visor/de-la-ira--0/ html/fefae560-82b1-11df-acc7-002185ce6064_2.htm\#2>. Consultado el 7 de junio de 2017. Peter Sloterdijk, Ira y tiempo. Ensayo psicopolitico, 2010, Madrid, Siruela, trad. de Miguel Ángel Vega Cernuda y Elena Serrano Bertos, p. 28.

${ }^{33}$ Friedrich Hegel, Lecciones sobre la filosofia de la historia universal, 2008, Madrid, Alianza, trad. de José Gaos, p. 83. 
las mentiras del mundo de mentiras; pasión por la justicia que no soporta el uso de personas convertidas en ganancias; pasión por condenar la sociedad que aprecia más las cosas muertas que las dolencias vivas; pasión para combatir la demencia del amontonamiento del poder sin rostro, que ha sobrepuesto esclavitudes, iniquidades y aniquilación de los encantos de la vida humana, pasión por las alturas y grandezas para despreciar las mediocridades miserables. Sin esta pasión, como esencia educativa, a nada de lo grande que requiere el mundo se podrá aspirar. Eliminada esta pasión del proceso educativo todo terminará en hombres de cabezas uniformes, de pensamientos cortados a la medida, valiosos y funcionales, para una sociedad desabrida de la política de comedia y de caricatura llagada, de la economía que sigue demostrando sus verdades numéricas en el pizarrón de las desigualdades mortales; en una sociedad aburrida que consume la belleza de los días en el juego de los gozos y placeres de las ofertas, demandas y utilidades. Sin esta pasión, la educación no vale la pena de ser vivida, no vale la pena ni de ser pensada. ${ }^{34}$

JRG - Profesor, ¿cuál fue su responsabilidad en ese comité que revisaba los cursos?

CI - El trabajo en torno al curso de Ideas e Instituciones Políticas y Sociales se dividió, y a mí me tocó revisar el curso de Ideas I y la mitad de Ideas II. Allí sí hubo una modificación considerable, insisto, y pienso que se conservó el espíritu de los cursos. El curso tenía una extensión mucho mayor; de hecho, el curso de Ideas tenía parte del Antiguo Testamento. Pero eso fue cuando me convertí en profesor de tiempo completo.

El Departamento de Estudios Generales aparece como pilar de la educación integral que ofrece el ITAM. Así lo piensa Marta Eugenia García Ugarte en la más completa y cuidadosa historia que se ha realizado sobre el ITAM. ${ }^{35}$ En esta obra de cuatro tomos que se publicó

${ }^{34}$ De la Isla, "Estudios Generales: Universidad dentro del tecnológico", pp. 104-105.

${ }^{35}$ Marta Eugenia García Ugarte, Tiempo y memoria. Historia del ITAM (1946-2016), 2017, México, El Equilibrista, 4 tomos. 
en 2017, encontramos este pasaje en el que se cita una reflexión de Carlos McCadden:

El ITAM es heredero de una verdadera tradición educativa centrada en la persona humana, que entiende que solo si conocemos y reconocemos lo que realmente somos podemos realizar la recta ambición de no contentarnos con la mediocridad, sino anhelar lo mejor y buscar conseguirlo con nuestras propias fuerzas [...] Nuestra comunidad está llamada por vocación esencial a buscar la verdad y el bien, lo cual realiza libre y responsablemente por medio del diálogo y el fomento del pensamiento crítico. ${ }^{36}$

El Departamento de Estudios Generales tiene a su cargo la impartición de los cursos: Ideas e Instituciones Políticas y Sociales en tres semestres, Problemas de la Civilización Contemporánea ${ }^{37}$ en dos semestres, Historia Sociopolítica de México ${ }^{38}$ y Problemas de la Realidad Mexicana Contemporánea. ${ }^{39}$

El doctor De la Isla tiene una interpretación propia de los tres cursos de Ideas. Los concibe como "el gran ejercicio para que la mente conozca, compare, se adhiera o rechace, y para que el estudiante y el maestro se nutran y puedan llegar a generar sus propias ideas que son

${ }^{36}$ Carlos J. Mc Cadden M., "El ITAM según Dr. Carlos J. McCadden”, El Supuesto, 11 de febrero de 2015, p. 3. Citado por Marta Eugenia García Ugarte, op. cit., t. III, pp. 840-841.

${ }^{37}$ Para comprender más detalladamente la naturaleza y los objetivos de los cursos de Problemas de la civilización contemporánea, recomiendo el texto de Julia Sierra Moncayo, “Qué son los Estudios Generales", Estudios 97 (2011), pp. 39- 59.

${ }^{38}$ Recomiendo el estudio de dos textos indispensables para conocer la finalidad y los contenidos de los cursos de Historia Sociopolítica de México y Problemas de la Realidad Mexicana Contemporánea: Reynaldo Sordo, "Historia sobre los cursos de México de Estudios Generales", Estudios 97 (2011), pp. 61-69, y Julia Sierra Moncayo, "Comentarios y reflexiones sobre los cursos de México”, Estudios 116 (2016), pp. 153-163.

${ }^{39}$ Para comprender la naturaleza, los objetivos, contenidos e interrelación de los cursos de Estudios Generales en el ITAM, es imprescindible el estudio de la ponencia del maestro José Ramón Benito Alzaga, "Estudios Generales en el ITAM", dictada en la Asamblea Nacional de ANFECA, en julio de 1973. La reflexión está centrada en el plan de estudios que estuvo vigente en el ITAM de 1969 hasta los cambios de 1981, cuando desapareció la asignatura de Métodos y Técnicas de investigación y la reestructuración de los cursos a partir de 1982 y el nacimiento de los cursos de Problemas de la civilización contemporánea. El texto está en línea en $<$ http://generales.itam.mx/sites/default/files/estudios_generales_en_itam.pdf $>$. Para una presentación actualizada de los cursos puede consultarse $<$ http://generales.itam.mx/es/42/paginas/materias $>$. 
el móvil de su existencia." ${ }^{40}$ Para él, los estudiantes deben dar a luz sus propias ideas, porque solo de ese modo las pueden defender como a sus hijos. "Estos cursos, tomándolos en vivo, generan espontáneamente la pasión por la verdad, por la justicia, por la grandeza, diferencia primordial de la educación del hombre humano." ${ }^{41}$ No solo se trata de acopiar y repetir el pensamiento de Platón, Aristóteles, Kant, Hegel o Heidegger, sino que el estudiante va descubriendo sus propias ideas y se faculta para juzgar.

Por otro lado, están los cursos de Problemas. El doctor De la Isla piensa que transitamos continuamente de las ideas a la vida y viceversa. Por eso, los cursos de Ideas y Problemas se retroalimentan:

Allí también, en los Estudios Generales, están los más graves problemas de nuestra civilización para transitar contiguamente de las ideas a la vida y a los problemas de la vida [El doctor De la Isla se refiere a los dos cursos de Problemas de la Civilización Contemporánea]. Desde las ideas los problemas adquieren otras dimensiones; se conocen mejor, se aprecian mejor sus angustias, urgencias y obscuridades. ${ }^{42}$

La intención de ordenar cinco materias de Problemas (dos cursos) e Ideas (tres cursos) antes de los cursos sobre México es evidente. Son una preparación para enfrentar el estudio de lo que nos resulta más próximo, la comunidad y el país al que pertenecemos. En los cursos de Historia sociopolítica de México y Problemas de la Realidad Mexicana contemporánea el estudiante puede emplear las ideas estudiadas y construir nuevas:

Y siempre auxiliados por la maestra historia, que por menospreciarla y desplazarla de la memoria, México ha sufrido terribles destrucciones, agresiones y ofensas [...] En ese sentido deberían considerarse los problemas de la realidad mexicana contemporánea, la materia, el curso más importante de todas las carreras, si hemos de tomar en serio el gran obje-

${ }^{40}$ De la Isla, "Estudios Generales: Universidad dentro del tecnológico", p. 103.

${ }^{41}$ Loc. cit.

${ }^{42} I d$. 
tivo institucional de colaborar en la construcción de una sociedad más libre, más justa, más humana." ${ }^{43}$

JRG — ¿Cómo era el ITAM de esa época?

$\mathrm{CI}$ - Al principio, el ITAM, tal y como lo encontramos, era una escuela de contadores y después de economistas que estaba en un proceso de reestructuración. De hecho, todo el departamento de Estudios Generales estaba sometido a una revisión que realizaba un comité constituido por las personas que le digo y que presidía el profesor José Ramón Benito. Pienso que él es un personaje fundamental en la fundación, consolidación y conformación del Departamento de Estudios Generales. El método dialógico ya existía, nosotros valoramos las antologías que venían de la Universidad de Nuevo León, bastante buenas, tomando en cuenta las limitaciones de la época y el método era usado en nuestras clases. Al mismo tiempo que dábamos las clases, íbamos revisando los materiales; no parábamos de reflexionar sobre los métodos, los contenidos y los objetivos de los cursos. Creo que fue un acierto tomar como punto de partida los libros y materiales existentes para ponernos en marcha. Recuerdo que el profesor Benito había relevado a otro profesor que participó en su etapa inicial, el doctor Diego Valadés. Había otros profesores, como Germán Plascencia, que se dedicaba especialmente a la materia de métodos. Otro acierto fue la inclusión de los cursos de México, sobre todo porque ayudaba a comprender la situación tan compleja por la que pasaba el país.

Como dijimos, los materiales o antologías del curso que se impartía en la Universidad de Nuevo León y del que partió el trabajo de revisión y ajuste en el ITAM tenían al diálogo como método central. El método del diálogo también había sido introducido en la Facultad de Economía de Nuevo León. Consuelo Meyer señala enfáticamente que los objetivos del curso, sus contenidos y sus materiales nunca estuvieron desvinculados del método del debate que se empleaba en las clases. Este aspecto que parece secundario, el referido al método, exige una breve reflexión.

${ }^{43} I d$. 
En realidad, el diálogo, como muestra Georges Gusdorf(1912-2000) en ¿Para qué los profesores?, no es un asunto de una disciplina instrumental, sino que es la esencia del acto educativo. ${ }^{44}$ Cuando se habla de "método dialógico" se predica un modo de hacer que corresponde con la finalidad y el acto mismo de educar. La lectio y la disputatio son un núcleo de actividades distintivas que se utilizan en la universidad desde su aparición en la Edad Media. En este sentido, el "método" que se utilizaba en Columbia College y que se usó en la Universidad de Nuevo León y en la Universidad de Chicago no es distinto, en espíritu, del que se instituyó en otras universidades, como Oxford, Salamanca o París. ${ }^{45}$ El estudiante "se presenta a clase después de haber estudiado cuidadosamente los materiales señalados para discusión, y dispuesto a hacer el análisis crítico de los mismos y exponer y sostener sus puntos de vista en una discusión generalizada que encauza el maestro". ${ }^{46}$

JRG — ¿Cómo describiría la docencia en el ITAM?

CI - Una de las cosas que más agradezco fue la libertad de cátedra. Nunca me sentí restringido para expresar lo que pensaba en ningún sentido. Yo siempre hablé con mucha libertad y tuve respeto de mis alumnos y de las autoridades del Instituto. Fui crítico, expresaba mis puntos de vista, y pienso que esa libertad debe garantizarse en toda universidad.

Según el Estatuto General del ITAM, capítulo segundo, artículo sexto, dedicado a la naturaleza universitaria, tres principios básicos norman la actividad del ITAM: la autonomía universitaria, la libertad de cátedra y el sentido comunitario. Sobre el segundo principio, dice a la letra: "La libertad de cátedra, con la responsabilidad que le es correlativa, como medio indispensable para el cumplimiento de sus funciones universitarias". ${ }^{47}$ El objeto de la universidad es la verdad dialogada, y si esta no se puede pensar o expresar, sería un obstáculo en su adquisición.

${ }^{44}$ Gusdorf, ¿Para qué los profesores?, 1969, Madrid, Cuadernos para el Diálogo, trad. de María Luis León Temblador y Carlos Rodríguez Sanz, 299 pp.

${ }^{45}$ Sobre este tema, puede verse con provecho Georges Gusdorf, L'Université en question, 1964, París, Les Éditions Payot, 223 pp.

${ }^{46}$ Meyer, "Prólogo", p. XIII.

${ }^{47}$ Estatuto General del ITAM, capítulo II, artículo 6. 
Este principio no hace otra cosa que expresar la filosofía educativa del ITAM, que se asienta e inspira "en un concepto que entiende al ser humano como ser libre, como ser social comprometido con la elevación y el progreso humano y como ser llamado por vocación esencial a buscar la verdad y el bien". ${ }^{48}$ Así, la educación debe orientar sus esfuerzos a "mejorar al ser humano mediante el enriquecimiento de sus mejores valores, la integración de su persona, la formación de su conciencia y el acrecentamiento de su capacidad de servicio". ${ }^{49}$

JRG - ¿Y los Estudios Generales?

CI - Después de tantos años, no tengo duda de que Estudios Generales es lo mejor que tiene el ITAM, el aspecto de mejor calidad, porque no solo hace técnicos, sino que representa la defensa de los valores humanos, sobre todo ahora que hay un predomino de la técnica. Es más, yo creo que el estudiante que realmente hace sus estudios generales termina pesándole más en su formación. Les deja un sello más definitivo. Sus recuerdos más significativos vienen de los cursos del Departamento de Estudios Generales, porque son la evocación de su misma humanidad. El reto es mantener la calidad de los cursos, la formación de la responsabilidad social de los alumnos; de lo contrario, las instituciones educativas no solo no hacen bien, sino que se vuelven perversas porque favorecen la desigualdad.

El proyecto educativo del ITAM tiene como marca de su calidad la formación impartida por el Departamento de Estudios Generales. Dice el doctor De la Isla:

Como constitutivo esencial al gran proyecto educativo [del ITAM] se pensaron las materias de los Estudios Generales, que merecieron la creación de un Departamento, con la inmensa responsabilidad de proporcionar a los estudiantes los mejores elementos para la edificación de la parte más importante de todo proyecto educativo, que es la formación humana que pretende ser integral. ${ }^{50}$

${ }^{48}$ Filosofia educativa del ITAM, en $<$ https://www.itam.mx/es/misi $\%$ C3\%B3n-objetivosprincipios-y-filosof\%C3\%ADa,>. Consultado el 7 de junio de 2017.

${ }^{49}$ Loc. cit.

${ }^{50}$ De la Isla, "Estudios Generales: Universidad dentro del tecnológico”, p. 102. 
A lo largo de la historia del ITAM, eminentes egresados, académicos, y expertos en educación se han percatado de que los Estudios Generales constituyen una de las columnas más fuertes con las que cuenta la institución. Su valor radica en su carácter integrador y su naturaleza preponderantemente formativa. Dice el doctor De la Isla:

Los Estudios Generales son una gran oportunidad, un gran medio para la educación del hombre humano. Allí está la fértil y fecunda llanura de cosmovisiones para que la inteligencia se alimente, para que se ejercite en la admiración, contemplación y valoración de las extraordinarias construcciones de conceptos de vida para la vida. ${ }^{51}$

No se trata de un elemento accesorio o complementario en el proceso de especialización de los individuos. Tampoco se trata de dotar de un tono intelectual al hombre técnico, sino que los técnicos y especialistas tienen como tarea más amplia la de ser hombres dentro de una cultura. Por eso, el elemento unificador es el hombre mismo y su dignidad. Así lo expresa el doctor De la Isla:

Pero sí existe un principio unificador capaz de vertebrar las infinitas divergencias de los intereses humanos. Ese principio unificador es el hombre mismo: el hombre es el único tema que logra interesar a todos los hombres, cualesquiera que sean sus grados de inteligencias o sus modos de existir. ${ }^{52}$

Sin este criterio integrador no podría darse verdaderamente una formación universitaria. El hombre necesita ser formado en su propia humanidad para insertarse de manera satisfactoria en su comunidad. El profesor José Ramón Benito lo expresa de esta manera:

La formación del hombre es la aspiración de todo humanismo y de toda cultura. Es común considerar como representativos y casi sinónimos de cultura y humanismo el cultivo de los clásicos y el estudio de problemas filosóficos, históricos y literarios, y ello se debe a que estas disciplinas, designadas con el nombre de Humanidades, han dado prueba por su

${ }^{51}$ Loc. cit.

${ }^{52}$ De la Isla, "Reflexiones en plural sobre un camino hacia lo humano en la educación superior", p. 9. 
"desinterés" e "inutilidad" de estar por entero dirigidas a la realización y expresión de lo humano, sin subordinación a ninguna otra cosa temporal. Los caminos y orientación que se han presentado son múltiples y muy diversos, pero en el seno de todos ellos late, vacilante e inextinguible, la misma llama: el amor al hombre. ${ }^{53}$

Por eso el especialista no solo debe conocer su técnica, sino cómo su técnica lo afecta a él mismo y a la sociedad, para que pueda situarse fecundamente en su tiempo y en su espacio, para que pueda orientarse cósmicamente:

Solo el hombre penetrado existencialmente de lo humano puede insertarse en la humanidad y este podría ser el camino de la educación hacia lo humano: Que el especialista no solo conozca la técnica de su especialidad o la especialidad de su técnica, sino también, inseparablemente, cómo su técnica o especialidad ha afectado, afecta y afectará a los hombres; que sea consciente de sus efectos en la persona, en la sociedad y en el plano económico, político, de integración o de cambio; que el técnico, especialista, profesional por diversos caminos, estudios y materiales posea sin excepción, como fundamento y esencia educativa, ese esquema de ideas sobre ellos mismos, sobre el mundo, su historia y sus problemas que le permita situarse con fecundidad humana en su espacio y su tiempo. ${ }^{54}$

\section{Los Estudios Generales:}

\section{Universidad dentro del tecnológico}

Hace algunos años, Carlos de la Isla tituló una de sus conferencias "Estudios Generales: Universidad dentro del tecnológico". El objetivo había sido formular una conceptualización integral de los estudios generales como parte del proyecto formativo del ITAM. Lo expresó de este modo: "Como casi todos ustedes saben, del programa de Estudios Generales se ha dicho que es la universidad dentro del tecnológico por

${ }^{53}$ José Ramón Benito, op. cit.

${ }^{54}$ De la Isla, "Reflexiones en plural...", loc.cit., p. 9. 
sus contenidos de universalidad y su estudio desde la perspectiva general (studia generalia)". ${ }^{55}$

¿Qué quiere decir con ello? ¿Es un simple juego de palabras, puesto que el término "estudios generales" proviene de la expresión studium generale, nombre que se le otorgó a la universidad europea en los siglos XII y XVIII, para referirse a las instituciones que habían alcanzado fama dilatada y combinaban las artes liberales con alguna especialidad?

Para comprender más adecuadamente la problemática que subyace en la expresión "la universidad dentro del tecnológico", resulta de utilidad el trabajo Pensar la universidad. Presente y porvenir realizado por Julia Sierra Moncayo y José Rafael González Díaz. El resto de esta sección está basada en ese artículo. ${ }^{56}$

Al escritor J. M. Coetzee, premio Nobel de Literatura 2003, le plantearon dos preguntas relevantes sobre la naturaleza y la misión de la universidad. La primera se refería a la autonomía y libertad académica y fue formulada en estos términos: ¿Una universidad sigue siendo universidad cuando pierde su autonomía académica? La segunda, que se relaciona con la misión de la universidad, fue: ¿Una universidad sin una facultad de humanidades sigue siendo una universidad?

El escritor y académico contestó que la universidad se encuentra al borde de la extinción. Su amenaza no proviene necesariamente del Estado, como ocurrió en otras épocas, sino del modelo económico y en el modo en el que se articulan las diversas ciencias modernas.

En todo el mundo, a medida que los gobiernos abandonan su deber tradicional de fomentar el bien común y se asumen como meros administradores de las economías nacionales, las universidades han resentido presiones para convertirse en escuelas de formación para equipar a los jóvenes con las habilidades que exige la economía moderna. ${ }^{57}$

${ }^{55}$ De la Isla, "Estudios Generales: Universidad dentro del tecnológico", p. 102.

${ }^{56}$ González Díaz y Sierra Moncayo, "Pensar la universidad. Presente y porvenir. Estudios Generales y el papel de la universidad en el diálogo intercultural", ponencia presentada en el VIII Simposio Internacional de Estudios Generales realizado en Bogotá, Colombia, el 17, 18 y 19 de noviembre de 2016.

${ }^{57}$ J.M. Coetzee, Universities head for extinction, en <http:// mg.co.za/article/2013-1101-universities-head-for- extinction>. Consultado el 13 de junio de 2017. 
En otras palabras, la pregunta por la autonomía académica también se vincula con la situación económica de las universidades: ¿Se puede tener autonomía académica cuando no se tiene autonomía financiera? Esta preocupación también está presente en voces tan autorizadas como Derek Bok, ${ }^{58}$ rector de la Universidad de Harvard en dos periodos, que en Universidades a la venta. La comercialización de la educación superior $^{59}$ advierte sobre los riesgos que entraña supeditar las acciones educativas a los criterios mercantilistas. Implica, en la práctica, poner a la venta los valores académicos y con ello desnaturalizar la universidad, como aparece claramente expuesto en la película Ivory Tower. ${ }^{60}$

Para Coetzee el deterioro de las universidades es el resultado de un verdadero asalto durante la década de 1980, puesto que no se podía permitir que la universidad fuera un factor de cuestionamiento y agitación social.

Siempre ha habido cierta falsedad en la afirmación de que las universidades son instituciones autónomas. Sin embargo, lo que las universidades padecieron durante las décadas de 1980 y 1990 fue bastante vergonzoso, pues con la amenaza de que les recortarían el financiamiento aceptaron convertirse en empresas comerciales, en las que profesores que antes realizaban sus investigaciones con libertad soberana, se transformaron en agobiados empleados que debían cumplir con cuotas fijadas, bajo el escrutinio de gerentes profesionales. Es muy dudoso que los antiguos poderes del profesorado lleguen alguna vez a restaurarse. ${ }^{61}$

Las instituciones educativas nunca pueden considerarse culturalmente autónomas. La educación existe en una cultura. Y la cultura no se encuentra exenta de los sistemas de recompensa, distinción e incluso poder que acompañan a otros fenómenos. La defensa de la autonomía

${ }^{58}$ Derek Bok nació en Pensilvania y enseñó derecho en Harvard desde 1958. Fue decano de la Escuela de Leyes y rector de la universidad hasta 2007. Su reflexión sobre la educación es abundante y sugerente. Ha examinado ampliamente las repercusiones de la economía de mercado sobre la educación universitaria.

${ }^{59}$ Bok, Universidades a la venta. La comercialización de la educación superior, 2010, Valencia, Universidad de Valencia, $240 \mathrm{pp}$.

${ }^{60} \mathrm{https}: / /$ www.youtube.com/watch?v=eLdU7uts4ws

${ }^{61}$ Coetzee, Diario de un mal año, 2016, México, Penguin Random House, trad. de Jordi Fibla, p. 46. 
quiere colocar a la educación más allá de cualquier presión, de manera que la escuela esté por encima de las luchas políticas, como si fuera ajena a esos intereses. Sin embargo, en cuanto institución cultural, la universidad no es ajena a la lucha por la distinción y el reconocimiento. Las instituciones culturales a menudo compiten para que sus méritos sean valorados por encima de las otras, pero esas competencias no pueden tener un solo ganador, porque las instituciones dependen unas de otras. Podemos decir que las universidades regatean distinciones y se someten al sistema de clasificación como sistema de evaluación heterónomo. Es el reconocimiento de los demás el que afirma el valor de la institución.

A Coetzee le parece una política equivocada y miope la que define los objetivos de la educación superior a partir de las necesidades transitorias de la economía. Sobre todo, porque una sociedad democrática y una economía nacional vigorosa requieren ciudadanos críticamente alfabetizados para explorar y cuestionar las suposiciones en las que se basan los paradigmas de la vida nacional y económica vigentes en una época.

Sin la capacidad de reflexionar sobre nosotros mismos, corremos un riesgo permanente de relajarnos y caer en un estado de complacencia. Y solo las descuidadas humanidades pueden proporcionar una formación crítica [...] La fuerza ideológica que impulsó el asalto a la independencia de las universidades en Occidente comenzó en la década de 1980 como una reacción a lo que las universidades estaban haciendo en las décadas de 1960 y 1970, es decir, alentando a las masas de jóvenes a que abrazaran la opinión de que había algo malo en la forma en la que se gobernaba el mundo y suministrándoles el alimento intelectual para una crítica de toda la civilización occidental. La campaña para librar a la academia de lo que se consideró como un malestar de izquierda o anarquista se ha prolongado décadas y ha tenido éxito a tal punto que concebir hoy a las universidades como semilleros de agitación y disidencia sería cómico. ${ }^{62}$

La respuesta de la clase política a las demandas de la universidad para alcanzar su autonomía frente al poder político ha sido eficaz. La universidad, en tiempo de crisis económica, es simplemente uno entre

${ }^{62}$ Loc. cit. 
muchos actores que compiten por fondos públicos o privados $\mathrm{y}$, si realmente creen en los elevados ideales que proclaman, deben demostrar que están preparadas para morir de hambre por sus creencias. La crisis de la universidad también se relaciona con el final de una fase de su historia que se inspiraba en el renacimiento de los ideales del humanismo de las universidades alemanas del siglo XIX. ${ }^{63}$

Este final ha ocurrido no solo porque los enemigos neoliberales de la universidad han logrado sus objetivos, sino porque quedan muy pocas personas que realmente creen en las humanidades y en la universidad constituida sobre bases humanistas, con estudios filosóficos, históricos y filológicos como sus pilares.

Sin embargo, la formación universitaria necesita las humanidades, aunque no necesariamente una facultad que se dedique a su cultivo. Algunos pueden sostener que solo las facultades de humanidades pueden enseñar a los estudiantes la formación crítica que permite a una cultura renovarse continuamente. Sin negar que esta formación es muy importante, es legítimo interrogarse si los estudiantes necesitan saber acerca de Hesíodo, Petrarca, Platón, Kant o Heidegger para adquirir esas cualidades. Las habilidades y conocimientos relevantes serían lectura, redacción, argumentación y el conocimiento de las grandes ideas, en las que se analizaran las principales cosmovisiones desde el mundo antiguo hasta el presente. ${ }^{64}$ Una serie de tales cursos no requerirá toda una facultad de humanidades, solo un departamento académico dotado de profesores brillantes y preparados. Los cursos de formación humanística no son nuevos. De hecho, se han establecido en innumerables universidades estadounidenses con diversos nombres como freshman composition, general education, liberal arts y otros.

${ }^{63}$ Coetzee, loc. cit.

64 "La buena literatura, a la vez que apacigua momentáneamente la insatisfacción humana, la incrementa, y, desarrollando una sensibilidad crítica inconformista ante la vida hace a los seres humanos más aptos para la infelicidad. [...] Esto es probablemente cierto, pero también lo es que, sin la insatisfacción y la rebeldía con la mediocridad y la sordidez de la vida, los seres humanos viviríamos todavía en un estado primitivo, la historia se habría estancado, no habría nacido el individuo, ni la ciencia ni tecnología habrían despegado, ni los derechos humanos serían reconocidos, ni la libertad existiría, pues todos ellos son creaturas nacidas a partir de actos de insumisión contra una vida percibida como insuficiente e intolerable." Mario Vargas Llosa, "La literatura y la vida”, en Elogio de la educación, 2016, México, Taurus, pp. 24-25. 
No hay nada de malo en argumentar que una buena educación humanística formará integralmente a un egresado crítico. Pero es un error afirmar que un sistema completo de educación humanista es la única manera de preparar a los estudiantes en el pensamiento crítico. Toda universitas es una humanitas; por ello, la universidad en su sentido más completo y en todas sus funciones de docencia, investigación y difusión aspira a la universalidad que sitúa en el centro de sus tareas al hombre; busca la unidad del saber, investiga no solo para entender un aspecto de lo real; busca apasionadamente la verdad y da luz a la sociedad sobre los problemas que le aquejan. Esta tarea sustantiva no se cumple solo porque una universidad tenga una facultad de humanidades, pues sin ella no puede ser considerada como universidad, pero también debe formar a los estudiantes integralmente y mantener un diálogo permanente con las otras facultades e instituciones sociales. Esto no significa que un instituto educativo, por carecer de una facultad de humanidades, esté impedido para ofrecer una formación universitaria humanista e integral. Las humanidades no solo deben estar al servicio de una habilidad para la crítica, sino a la investigación libre que es un valor en sí mismo.

La condición de la universidad en la actualidad es el reflejo de una crisis cultural y de la ciencia misma. La universidad es el espacio privilegiado para el diálogo cultural. Se aprende en esa interacción constante y se coloca la realidad en ella.

¿Qué quiere decir Carlos de la Isla cuando advierte que los Estudios Generales son la universidad dentro del tecnológico? Quiere decir que sin este departamento de humanidades, la formación del ITAM no sería verdaderamente universitaria.

Los alumnos tienen una formación técnica rigurosa que resulta muy atractiva para el mercado laboral e incluso puede ser considerada por algunos como objeto de compraventa. Entre tanto, la formación de los Estudios Generales, la universidad dentro del tecnológico, tiene la mira más allá y procura que el estudiante adquiera una conciencia de que no puede verse a sí mismo como un simple medio para generar dinero, que necesita descubrir su propio valor y de las personas que le rodean. Necesita enriquecerse como ser humano. Por eso mismo, esa 
formación especializada debe subordinarse al bien de la persona y de la comunidad a la que pertenece. Robert Hutchins (1899-1977), rector de la Universidad de Chicago y promotor de los famosos Great Books, defendía que "solo una educación concebida como crecimiento moral, intelectual, estético y espiritual puede realizar esos objetivos [que la persona se comprenda a sí misma y el mundo en el que vive y participe como ciudadana en los asuntos públicos]". ${ }^{65}$ Por eso, la universidad debe ser libre y hacer libre al hombre para darle sentido a su existencia y vivir conforme a la sabiduría:

CI - En los años en que tuve el privilegio de pertenecer al ITAM, luché muchísimo, y pienso que se debe seguir luchando porque no prime la cantidad por encima de la calidad, que prime lo sustancial, los valores universales, para que la universidad como conciencia crítica de la sociedad permanezca libre y al servicio del hombre y su dignidad.

La universidad libre para los hombres libres que les permite elevarse sobre la mediocridad y el culto a la mera utilidad. Desde que era un joven profesor, Carlos de la Isla citaba a Pier Paolo Vergerio (1498-1565) y la definición del siglo XIV del tipo de educación liberal:

Llamamos "liberales" a los estudios que son dignos de un hombre libre, aquellos por los que se busca y ejercita la sabiduría y no el lucro y el placer, que son los estímulos de la acción de los caracteres vulgares. La educación es liberal porque libera de la esclavitud de los exclusivos intereses utilitarios y es humanista en cuanto forma la humanitas" ${ }^{66}$

CI - Terminamos la conversación, discúlpeme profesor. Tengo algunas responsabilidades, pero podemos seguir en otro momento.

${ }^{65}$ Robert Hutchins, Educación y universidad en utopía, 1968, Buenos Aires, EUDEBA, trad. de Noemí Rosenblatt, p. 16.

${ }^{66}$ Vergerio, "De ingenuis moribus et liberalibus adulescentiae studiis", op. cit., p. 29. 
Salí de su casa. Regresé al barrio de las fachadas coloniales de San Ángel y sus alrededores. ${ }^{67}$ La historia de esta localidad comenzó con la fundación de un Colegio, el de San Ángel Martin (1615), por mediación de los carmelitas. Con el paso del tiempo, el nombre de San Ángel terminó por designar a esta parte de la ciudad. Todo ello me hizo pensar en que la historia de la humanidad es custodiada por la integridad de los profesores que, como Carlos de la Isla, nos hacen conscientes de nuestra propia humanidad. Sus obras perduran como cultura viva de generación en generación.

${ }^{67}$ El barrio de San Ángel y sus alrededores obtuvieron en 1934 la declaratoria de "pueblo típico pintoresco" y en 1987 la declaración de "zona de monumentos". 